INOVAÇÃO SOCIAL

Reflexões Metodológicas 


\section{SOBRE A AUTORA}

Germana Gonçalves de Araujo I germana_araujo@yahoo.com.br

Lattes: http://lattes.cnpq.br/5486386468044529

Professora do Curso de Design Gráfico/DAVD/UFS, desde 2010. Doutora em Pós-Cultura pelo IAHC/UFBA (2013). Após graduar-se em Desenho Industrial/UFPB (2000), desenvolveu projetos em design para o terceiro setor. Em 2011 a 2016, foi premiada pelo projeto gráfico de algumas obras. 


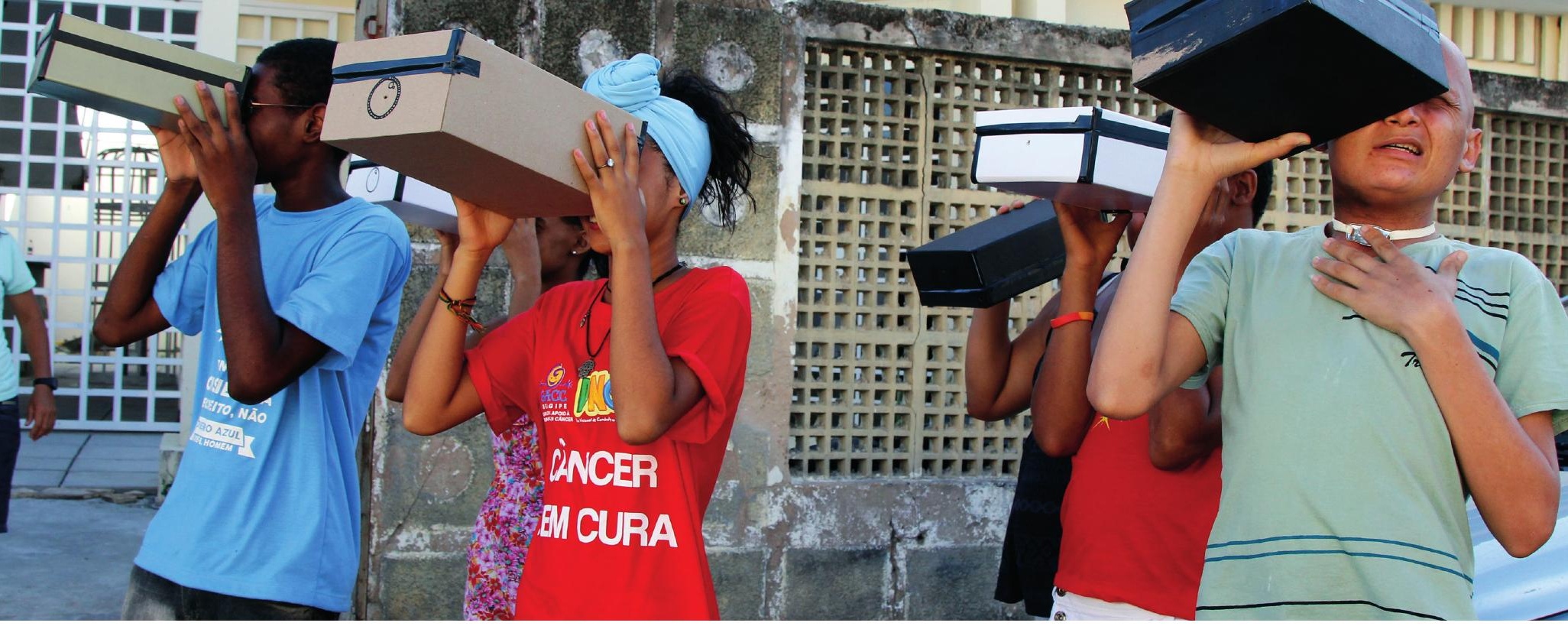

\title{
Design fora do centro: reflexões metodológicas em design a partir de um projeto social em Sergipe
}

\author{
Design out of the center: methodological \\ reflections in Design from a social project in \\ Sergipe
}

Germana Gonçalves de Araujo

\section{Resumo}

A ideia deste texto é propor uma reflexão sobre as abordagens metodológicas em design a partir do projeto Premissas do Design Aplicadas ao GACC Sergipe. Acreditando-se que, diante da complexidade do mundo, novas abordagens metodológicas se tornam necessárias para a projetação em designer, o referente projeto foi iniciado a partir de cinco premissas e não da identificação de problemas. Alunos do curso de Design da Universidade Federal de Sergipe refletiram, inicialmente, acerca da relação do Grupo de Apoio a Crianças com Câncer de Sergipe (GACC) com a sociedade e, a partir do diálogo com a instituição, configuraram as proposições.

Palavras-chave: Design Social; Metodologia Participativa; Câncer Infantil.

\section{Abstract}

This text claims to propose a reflection on the methodological approaches in Design through the project 'Design assumptions applied to GACC Sergipe.' Believing that, by facing the complexity of the world, new methodological approaches become necessary for a projection in Design; therefore, this project did not start with the identification of problems but from five assumptions. Students majoring in Graphic Design at the Federal University at Sergipe reflected initially on the relationship between the Group of Support to Children with Cancer of Sergipe (GACC) and the society, and then from dialogue with the institution, they set their propositions. 


\footnotetext{
${ }^{1}$ Para aprofundar o conhecimento sobre a história da Bauhaus (Staatliches Bauhaus, escola alemã fundada por em 1919 e encerrada em 1933), existem, atualmente, uma diversidade significativa de referências bibliográficas possíveis. Para a escritura desse artigo, foi consultada a obra de Rafael Cardoso intitulada Uma introdução à história do design (vide referências: (ARDOSO, 2008).
}

\section{INTRODUÇÃO}

Uma prática profissional técnico-artística que nasce e se fundamenta para atender às necessidades cotidianas humanas, o design, na realidade, surgiu junto à história da industrialização com o propósito de potencializar a produção em massa de objetos. Ou seja, o atendimento ao setor fabril, visando à dinâmica da economia de localidades, é o que tornou o design uma atividade compreendida como útil junto à sociedade.

No início do século $X X$, nas oficinas de ensino e ateliers de profissionais, objetos eram criados em consonância com as capacidades tecnológicas da época e, dessa maneira, a função e a aparência de um produto promoviam novos desejos de consumo e, consequentemente, o universo simbólico de determinadas localidades ampliavam-se. Ou seja: as práticas culturais passavam a ser exercidas por novos hábitos a partir da inserção de novos objetos. Entretanto, os métodos de estudo e projeto eram basicamente voltados para a compreensão de materiais e processos, e não para as mudanças possíveis causadas pela dinâmica da cultura.

Inicialmente, também considerando a mítica escola alemã Bauhaus ${ }^{1}$ como um berço da formação profissional em design no âmbito mundial, o foco não poderia ser nas pessoas, e o próprio ensino de design priorizava o ato prático de conceber objetos em oficinas criativas, sem que o profissional pudesse estabelecer diálogo com públicos ou realidades diferentes das dele. 0 ensino da Casa de Construção Estatal, a escola Bauhaus, aliava a arte com a técnica e propunha o ato prático de produzir o artesanato como uma função pedagógica, prevendo que, dessa maneira, os designers e arquitetos teriam a capacidade de projetar produtos para a indústria com qualidade estética e construtiva.

Uma questão relevante desse "início" da história do design, que desabilita a possibilidade de o designer buscar o diálogo com determinados grupos antes de iniciar seu processo criativo, é a ideia de que pressupostos universais deveriam orquestrar a industrialização e a comunicação de serviços e objetos. 0 uso de tipografias humanistas, sinais gráficos econômicos de carga cultural, 
objetos projetados para atender às ditas necessidades básicas de qualquer pessoa - independentemente das características socioculturais de onde ela vive - eram alguns dos requisitos obrigatórios para a prática em design. 0 não saber lidar com determinados aspectos de natureza social, incita o designer, até hoje, a tomar decisões de modo arbitrário. ${ }^{2}$

Mesmo hoje em dia, uma gama significativa de designers atua, geralmente, nos bastidores da produção e ficam invisíveis ao público. Ficar fora da cena, o que não necessariamente é estar fora do centro, significa, inclusive, que o profissional em design pode não assegurar responsabilidade social, ou mesmo ter o controle de algo que foi projetado por ele. E, sem ter a intenção de adensar sobre a questão, releva-se que se manter longe da realidade de públicos pode ser uma atitude de resiliência do designer quanto às questões socioculturais e políticas de um contexto, já que, para tomar parte e ciência de determinados conteúdos, é obrigatoriamente necessário vivenciar contextos e constituir diálogos.

Felizmente, o designer é impulsionado a sair do chão de fábricas ou dos birôs de escritórios e se deparar com um mercado de consumo saturado, sociedades marcadas pelas desigualdades, pela falta de consciência de classe, por ecossistemas em processo de esgotamento e crises econômicas. Afastar-se do interior de ambientes, seja de oficinas de criatividade, de ateliers e escritórios, ou mesmo de fábricas, fez com que o designer compreendesse a existência de realidades com especificidades socioculturais e, assim, passasse a abranger novas formas de atuação junto à sociedade, obrigando-se a refletir sobre seus próprios métodos projetuais. Sabe-se que abordagens de estudo e pesquisa de outros campos de conhecimento - como da antropologia, sociologia e neurociência - já são apropriadas por designers para orientar os processos de compreensão social da cultura de contextos. Cardoso, em seu livro Design para um mundo complexo, escreve que o designer, atualmente, deve saber lidar com um número significativo de variáveis inimagináveis há trinta anos.

O termo "design complexo" surge para caracterizar a produção no campo de design na contemporaneidade, compreendendo que métodos projetuais e técnicas de criatividade precisam ser revistos para dar

\author{
2 O que se está tentando alertar aqui \\ com "modo arbitrário" é a maneira \\ de projetar, por parte do designer, \\ sem a prática de estudos e pesquisas \\ que possam nortear um processo \\ criativo congruente com a realidade de \\ determinados contextos socioculturais. \\ Sendo assim, tendo apenas seu \\ próprio repertório como fonte de \\ informação, o designer pode pender a \\ uma proposição leviana.
}

Reconhecer a complexidade do sistema já é um grande avanço. Se todos adquirirem alguma consciência do tamanho e do intricado das relações que regem o mundo hoje, será possivel caminhar coletivamente e direção a um objetivo, seja lá qual for. O grande inimigo é sempre a ignorância, e as ideias preconcebidas que derivam da falta de exercício do pensamento. (CARDOSO, 2012, p. 43) 
3 Para conhecer mais sobre o Atelier Populaire, além das inúmeras possibilidades existentes na internet, sugere-se consultar Neves (2011) e Miyashiro (2011), autores referenciados na bibliografia deste texto. passagem a processos de inserção sociocultural, tornando possivel que o designer tenha lucidez sobre a relação da sociedade, organizada em moldes do complexo capitalismo atual, com a mecânica da produção de bens materiais e simbólicos, o qual, inclusive, transforma a informação na mercadoria mais valiosa (RUBIM, 2000, p. 4).

É diante da complexidade do mundo que novas abordagens se tornam necessárias nos processos de projetação para o designer. Releva-se que a reflexão sobre as maneiras com as quais o designer pode atuar aproximandose da sociedade foi empreendida por alguns estudiosos na área e, dessa maneira, além dos conceitos, os próprios métodos passaram a adjetivar os processos projetuais. Ou seja, a abordagem metodológica passa a ser o valor maior de um projeto. Consequentemente, pode-se desabilitar, ou desvalorizar, que o designer proponha resultados mais intuitivos e artísticos.

Nesse panorama histórico, releva-se que foi a partir dos anos de 1960 que acontecimentos sociais incitaram o desenvolvimento do design sob a perspectiva do uso de abordagens metodológicas centradas nas pessoas. Uma referência bastante citada entre autores é o Atelier Populaire, ${ }^{3}$ grupo formado em maio de 1968 por artistas, estudantes e trabalhadores que ocuparam a Escola de Belas Artes de Paris para a produção de uma "grande quantidade de material contra a sociedade burguesa e a favor da arte a serviço da sociedade" (NEVES, 2011, p. 55). Em 1968, cartazes e jornais, produzidos pelo grupo, passaram a circular pelas ruas tumultuadas de Paris, em um momento de turbulências social provocado pelo movimento estudantil e pela greve geral de trabalhadores.

Deve-se ter em vista que, entre 1960 e 1970, outros movimentos ao redor do mundo, também com o foco na mudança social, aconteceram simultaneamente ao Atelier Populaire. 0 autor Rafael Tadashi Miyashiro, em seu artigo sobre o design gráfico com preocupações sociais, explicita a fala da designer e autora inglesa Liz Mcquiston, que diz: "Muitas dessas organizações e movimentos que lutavam por mudanças sociais nesse período encontravam no design gráfico uma ferramenta para contestar a sociedade e exigir mudanças" (MCQUISTON apud MIYASHIRO, 2011, p. 66). Miyashiro também escreve que o design gráfico do centro ou "oficial", como o autor coloca, desse mesmo período "se consolidava no mundo corporativo com o 
estabelecimento de cânones e práticas ligadas ao Estilo Tipográfico Internacional" (MIYASHIRO, 2011, p. 66). Releva-se que obras literárias cânones sobre a história do design mundial, como o livro História do design gráfico dos autores Philip Meggs e Alston Purvis, não reconhecem o design gráfico fora do centro, responsável pela produção da comunicação de movimentos com o objetivo de transformação social, como o próprio Atelier Populaire, movimento que sequer é mencionado nessa obra.

Em meados do século XXI, as sociedades apresentavam uma dicotomia. Por um lado, a potência econômica e produtiva dos Estados Unidos ${ }^{4}$ estimulava a sociedade a descartar os objetos em curto tempo, com o propósito de manter as taxas de produtividade desejadas (CARDOSO, 2012, p. 164); por outro, buscando participar de um mundo mais democrático e socialmente justo, designers que evocavam preocupações sociais buscavam exercer suas atividades projetuais em consonância com os acontecimentos políticos e econômicos das localidades. ${ }^{5}$ Enquanto a demanda de uma população urbana com o poder aquisitivo crescente incentivou a tecnologia, que por sua vez fomentou a produção em massa, abaixando os custos e aumentando a oferta, o designer assumiu o importante papel social de interpretar os bens materiais e imateriais de determinados contextos, tornando-se um interpretador de códigos socioculturais. Surgem, então, abordagens que sugerem a participação direta e indireta de pessoas comuns nas equipes projetuais de designers, como o chamado design emocional, design participativo, design thinking e design interpretativo, dentro de uma perspectiva metodológica que propõe a observação, a escuta e o diálogo com públicos em determinadas realidades socioculturais. Entretanto, embora a maior parte dessas abordagens tenda a propor uma comunicação direta do designer com um público, não o faz necessariamente por preocupações sociais e, sim, por possibilitar o favorecimento do mapeamento do gosto e anseios de consumo de determinados grupos - as chamadas necessidades do público-alvo. É sempre importante lembrar que o designer que trabalha para o mercado nem sempre está no controle da situação de projeto e, por isso, dificilmente consegue colocar suas preocupações sociais, se as tiver, em consonância com as variáveis estabelecidas para delimitar as escolhas ao longo do processo projetual.

\begin{abstract}
4 "Enquanto o ensino do design no Brasil dava os primeiros passos e o país experimentava sua recente industrialização, na Europa e nos Estados Unidos o design já havia se estabelecido como profissão" (NEVES, 2011, p. 50).
\end{abstract}

\author{
${ }^{5} \mathrm{O}$ design participativo surgiu na \\ Escandinávia, no final dos anos de \\ 1960, com a perspectiva de estabelecer \\ uma gestão mais democrática do design \\ de sistemas/produtos no contexto da \\ informatização dos postos de trabalho. \\ A partir de 1980, essa abordagem \\ passou a ser empregada como \\ metodologia de design de produtos, \\ processo e interfaces (MORAES; SANTA \\ ROSA, 2012, p. 17).
}


Eu vejo o designer como tendo três possibilidades de introduzir seu próprio talento para a cultura. A primeira é por meio do design, que é, fazendo coisas. A segunda é por meio de uma articulação crítica acerca das condições culturais que elucidam o efeito do design na sociedade. E a terceira possibilidade é por meio da condução de um engajamento político. Muito do poder que afeta todas as formas do design está nas mãos. (MARGOLIN, 2016, p. 150)
${ }^{6}$ Para saber mais sobre o Grupo de Apoio à Criança com Câncer acessar conteúdos disponivel em: www.gacc-se. org.br.
A autora Flávia de Barros Neves, em seu artigo sobre engajamento político-social por meio do design gráfico, discorre sobre o conceito de "design cidadão" (NEVES, 2011, p. 47), publicado pelo designer norteamericano Victor Margolin em um ensaio na revista Design (2006). Esse conceito, reforçando um pensamento que foi iniciado nos anos de 1960, "[...] indica como os designers podem agir para pôr realmente em prática a essência do discurso atual do design ético e socialmente responsável" (NEVES, 2011, p. 49). Crítico do sistema capitalista, Margolin, segundo Neves, discorda de projetos em design que visam apenas a obtenção de lucro, e explicita que o designer é, antes de qualquer coisa, um cidadão, e deve trabalhar com responsabilidade moral e social, projetando objetos verdadeiramente úteis à sociedade. Diante da crença de Margolin, releva-se que a natureza do projeto e a personalidade do designer devem alinhar-se para que seja possível o desenvolvimento de projetos dentro da concepção do chamado design essencialmente para a sociedade.

Diante do que foi desenvolvido por Margolin, releva-se que, dificilmente, um profissional em design que iniciou sua carreira como um componente da mecânica do mercado de consumo e não teve a chance de vivenciar outra maneira de exercer sua prática conseguirá enxergar um modo de se inserir em projetos de cunho social ou de engajamento político.

Nesse sentido, tratando-se da experiência de atuar fora do eixo mercadológico, é que, em uma disciplina de Metodologia do Projeto em Design do Curso de Design da Universidade Federal de Sergipe (UFS), o projeto GACC Sergipe ${ }^{6}$ foi desenvolvido.

\section{PREMISSAS DO DESIGN APLICADAS AO GACC SERGIPE}

Releva-se que a ideia desse texto é propor uma reflexão sobre as abordagens metodológicas de projetos em design a partir dos desdobramentos do projeto Premissas do Design Aplicadas ao GACC Sergipe. $O$ referente projeto foi iniciado a partir de cinco premissas anunciadas em sala aula que incitaram os alunos a refletir acerca da relação do GACC com a sociedade: 1) a marca é uma troca simbólica; 
2) o aprendizado pode proporcionar a cura; 3) ser voluntário para ter ganhos mútuos; 4) a autoestima floresce o amor; 5) a sustentabilidade econômica pode garantir uma vida. Em atividades de grupo, os alunos se depararam com as questões anunciadas e desenvolveram possibilidades projetuais. $O$ intuito de envolver os alunos com as causas do GACC Sergipe foi de tornar oportuno, aos alunos do curso de Design da UFS, uma consciência perceptiva mais humanista sobre projetar com alternativas criativas, considerando a possibilidade de atuação em design fora da mecânica do capitalismo, da sociedade de consumo agressivo e da produção em massa de objetos.

As metodologias do design, tradicionalmente, têm o ponto inicial em um problema projetual. Como explicita o lendário Bruno Munari (1907-1998) em sua obra Das coisas nascem coisas - obra publicada originalmente em italiano, em 1981 (Da cosa nasce cosa), traduzida e reimpressa no Brasil, pela segunda vez, nos anos de 2000, que permanece bastante visitada no ensino do design.

A fala de Munari, ao lado, é significativa quando se está tentando delimitar a noção do que se entende por "problema projetual". É notório que, para Munari, não somente por intermédio da citação acima, todo o processo de projetação é iniciado por um fator determinante, que ele chama de "problema". Em um segundo momento, Munari sugere que o designer decomponha esse problema em seus componentes, o que, segundo ele, é um princípio do método cartesiano do filósofo francês do século XVII René Descartes (1596-1650). ${ }^{7}$ Esse método de Munari é uma abordagem projetual linear, estimulando a ideia de que o designer tem a capacidade de projetar mesmo estando afastado do contexto analisado.

No projeto do GACC Sergipe, desenvolvido dentro de uma perspectiva colaborativa, na qual o designer deve submeter-se a experiências em determinados contextos para possibilitar o diálogo com grupos e, somente assim, conciliar proposições, a noção de problema colocada por Munari foi desapreciada. Na realidade, crer que a partir de uma curta compreensão ${ }^{8}$ é possivel ter clareza sobre a natureza do projeto a ser desenvolvido é uma ilusão. Dizer que um designer é capaz de identificar problemas sem antes conviver e estabelecer diálogos é acreditar que as redes de relações socioculturais em determinadas localidades podem ser desvendadas a partir da compreensão objetiva
É necessário, portanto, começar pela definição do problema, que servirá também para definir os limites dentro dos quais o projetista irá trabalhar. Vamos supor que o problema seja projetar uma luminária. Será preciso estabelecer se se trata de uma luminária de mesa, de parede ou de escritório, de sala de estar ou de mesa de cabeceira. Se vai ser de incandescência ou fluorescência, de luz diurna ou qualquer outra. Se vai ter um preço limite, se vai ser distribuída nas grandes lojas, se deve ser desmontável ou articulável, se deve ter um termostato para regular a intensidade luminosa, e assim sucessivamente. (MUNARI, 1998, p. 32)

\footnotetext{
7 Pensa-se que não é cabivel neste texto ampliar conteúdo sobre o filósofo René Descartes (1596-1650), citado aqui apenas pela perspectiva do Bruno Munari.
}

\footnotetext{
8 "Curta compreensão" no sentido de falta de solidez. Pensa-se, aqui, que gerar consistência sobre algo a partir do "olhar" deve estar intimamente ligado à possibilidade de aprofundamento e que, somente por intermédio de processos que possam amplificar a percepção sobre esse algo - como estudos e pesquisas, além de residências e convivências - é possivel afugentar-se da compreensão limitada sobre as coisas.
} 
${ }^{9}$ Esse termo foi desenvolvido pelo historiador Durval Muniz Albuquerque Júnior que, em sua obra Fragmentos do discurso cultural: por uma análise crítica do discurso sobre a cultura no Brasil, discorre que "em qualquer sociedade humana, o que caracteriza a produção cultural sempre foram as misturas, os hibridismos, as mestiçagens, as dominações, as hegemonias, as trocas, as antropofagias, as relações enfim" (ALBUQUERQUE JÚNIOR, 2013, p. 20). sobre os fatos. Como desenvolve a designer espanhola Monica Pujol Romero, "pressupostos ontológicos estimulam a crença na possibilidade de um design como disciplina social objetiva e livre de valores, na qual o designer está distanciado da cena que está sendo analisada por meio do rigor e da técnica do método projetual" (ROMERO, 2011, p. 19).

A autora, em seu texto acerca das abordagens metodológicas em design como paradigmas, discorre sobre essa questão e nos alerta sobre a perspectiva projetual que se baseia em um problema, considerando um "paradigma funcionalista" o método projetual que é "[...] baseado na suposição de que a realidade tem uma existência objetiva [...] com caráter sistêmico orientado a produzir um estado ordenado e regulado de acontecimentos [...]" (ROMERO, 2011, p. 18). Esquece-se, então, que a cultura é um organismo dinâmico, e que a todo o momento novas redes de relações são constituídas, assim como antigas relações passam por processos de "desinvestimento de sentido".9 Nesse direcionamento, de destituir o "problema" do ponto de partida, como acontece na perspectiva munariana, e assumindo que para definir qual metodologia é apropriada para o desenvolvimento do projeto em design deve-se ter clareza sobre o que caracteriza e define determinada visão da realidade, assim como quais são as possibilidades de interação com essa realidade, foi que aconteceu a abordagem projetual colaborativa de natureza interpretativa no projeto desenvolvido por alunos de graduação em Design com o GACC Sergipe.

Corroborou-se com a ideia de Romero de que "[...] o que se entende como realidade está composto pelos pontos de vistas dos participantes na ação, ou seja, o produto das experiências subjetivas e intersubjetivas dos indivíduos" (ibid., p. 19), e sendo assim, "[...] o designer que compartilha esta visão de mundo e faz parte dela, procura compreender o processo de sentido por meio das múltiplas realidades compartilhadas que surgem se mantêm e mudam constantemente" (ibid., p. 20). Ou seja, segundo a autora, o designer que utiliza essa perspectiva para exercer sua prática não soluciona problemas, mas "[...] participa de um enunciado que já começou e seu objetivo é justamente o de entrar nesse diálogo" (ibid., p. 20). 
O projeto Premissas do Design Aplicadas ao GACC foi desdobrado em seis projetos, que podem ser esquematizados pelo esquema a seguir.

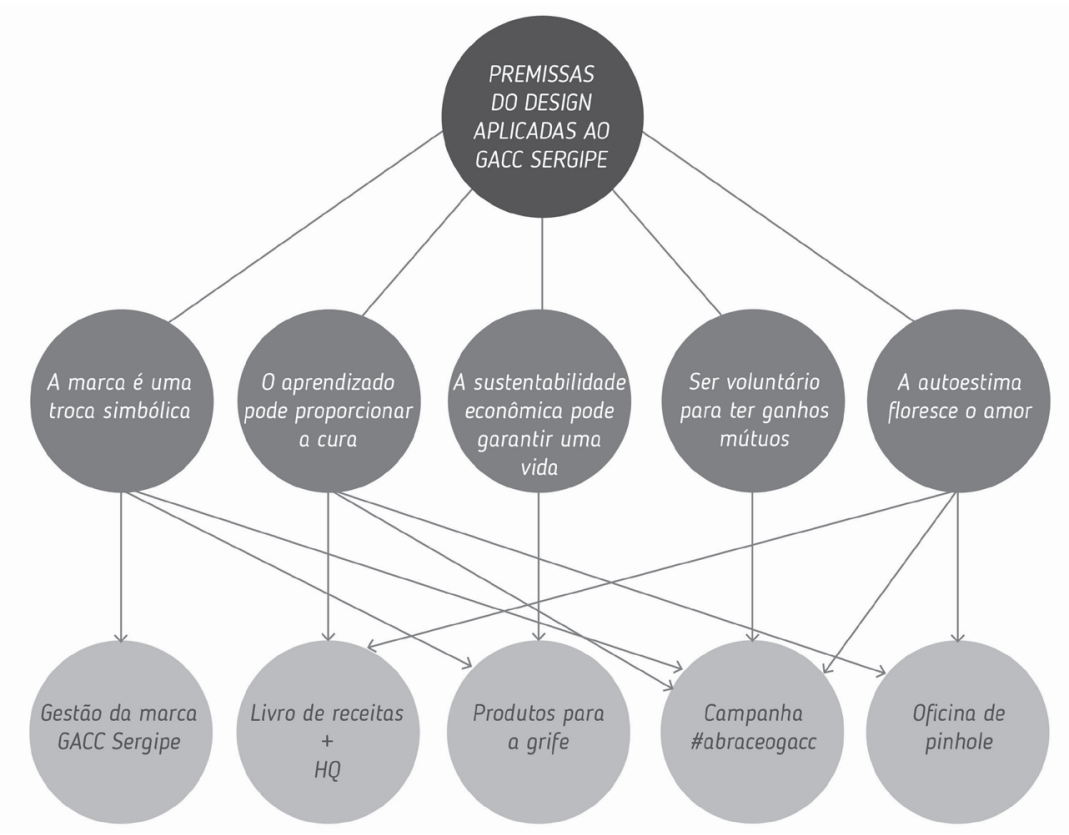

Esquema gráfico que apresenta a relação entre os projetos desenvolvidos a partir das premissas ou não de problemas. Apesar de cada projeto ter sido desenvolvido por grupos de alunos diversos, algumas compreensões, obtidas por intermédio de estudos e diálogos, foram compartilhadas entre eles e, assim, tornaram-se imprescindiveis para as proposições dos produtos. Fonte: Acervo do projeto.

Compreende-se, aqui neste texto, que as premissas são indagações que devem ser observadas por diversos ângulos a ponto de se obter uma provável proposição, uma possibilidade de projeto. A averiguação sobre o quão real a própria premissa é deve ser o primeiro passo. Nesse sentido, questionar se "a marca é uma troca simbólica" (a primeira premissa anunciada) fez com que os alunos buscassem compreender, primeiramente, de que modo é possível estabelecer uma relação mútua de sentido entre a marca do GACC com a sociedade. Assim, no passo seguinte ao do diálogo com a instituição (após a análise do discurso institucional do GACC Sergipe), foi necessário estabelecer diálogo com a realidade da sociedade civil, para compreender quais elementos que compõem a marca GACC geravam uma interpretação afetiva pelo interpretante, interferindo na aproximação da sociedade e, consequentemente, no envolvimento com 
10 "Consoante com o Plano Nacional de Extensão Universitária (PNE, 2003), a política de extensão da UFS tem como pressupostos o processo educativo, cultural e científico, articulador do ensino e da pesquisa de forma indissociável e viabilizador da integração da Universidade com a Sociedade, que se materializam por meio de programas, projetos, eventos e prestação de serviços" (PROEX, 2016).

${ }^{11}$ Ver apresentação do projeto em vídeo produzido pelos alunos, disponivel em: <youtu.beleyOnbeOuBlo>. Acesso em: 30 mar. 2017.

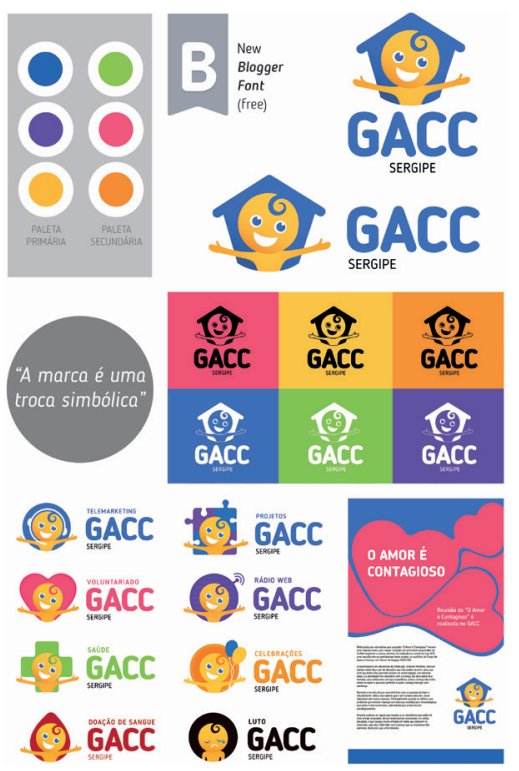

Painel panorâmico do projeto de gestão da marca GACC Sergipe, resultado da premissa "A marca é uma troca simbólica". Fonte: Acervo do projeto. as causas da instituição, tanto para estimular a contribuição financeira, quanto para a promoção do voluntariado.

Durante todo o processo, a abordagem foi colaborativa entre os alunos e o GACC, e o acordo entre as partes foi imprescindivel para o desenho dos projetos. Com a perspectiva multidisciplinar, discentes e profissionais de outras áreas, como Gastronomia e Audiovisual, foram convidados para acrescentar conhecimentos às equipes de projeto. Transcendendo o tempo e espaço da sala de aula, 23 alunos, sob a coordenação da docente da disciplina, assumiram a continuidade dos projetos em formato de projeto de extensão universitária ${ }^{10} \mathrm{e}$, junto com $\mathrm{o}$ apoio de três profissionais (um designer, uma nutricionista e uma gastróloga) desenvolveram seis projetos simultâneos durante o período de um ano, como apresentam os quadros a seguir: ${ }^{11}$

\begin{tabular}{|c|c|}
\hline PREMISSA & A marca é uma troca simbólica \\
\hline OBJETIVO & $\begin{array}{l}\text { Gerenciar a marca GACC Sergipe, a partir do } \\
\text { conhecimento da relação semântica (significados) } \\
\text { e da experimentação estética dessa marca com os } \\
\text { possíveis pontos de contato. }\end{array}$ \\
\hline PROPOSIÇÃO & $\begin{array}{l}\text { Valendo-se de uma pesquisa de opinião pública } \\
\text { (amostra aleatória), e após o diálogo com pessoas da } \\
\text { instituição, os alunos envolvidos com esse projeto } \\
\text { propuseram mudanças gráficas na marca GACC } \\
\text { Sergipe. A mudança no desenho da marca sugere } \\
\text { significados inalcançáveis no desenho existente } \\
\text { anteriormente, como acolhimento familiar e possível } \\
\text { proposição semântica do desenho da silhueta de } \\
\text { uma casa, para transmitir o amparo da instituição } \\
\text { para com seus assistidos. Releva-se que alguns } \\
\text { elementos existentes no desenho da marca anterior } \\
\text { às mudanças foram mantidos, já que, durante as } \\
\text { pesquisas, obtiveram-se informações de que esses } \\
\text { elementos gráficos já tinham sido instalados de modo } \\
\text { positivo no repertório das pessoas. }\end{array}$ \\
\hline
\end{tabular}




\begin{tabular}{|c|c|}
\hline PREMISSA & O aprendizado pode proporcionar a cura \\
\hline PROJETO & $\begin{array}{l}\text { Revista de histórias em quadrinhos (HQ), contando } \\
\text { histórias com base na vida real de assistidos, para } \\
\text { trabalhar, entre outros temas, o diagnóstico precoce e } \\
\text { a capacidade de superação da criança durante e pós- } \\
\text { tratamento do câncer. }\end{array}$ \\
\hline OBJETIVO & $\begin{array}{l}\text { Criar uma HQ com o propósito primeiro de tratar } \\
\text { questões como o diagnóstico e a superação de uma } \\
\text { criança com câncer. }\end{array}$ \\
\hline PROPOSIÇÃO & $\begin{array}{l}\text { Depois da compreensão de quais linguagens (verbais } \\
\text { e não verbais) seriam mais apropriadas para a } \\
\text { configuração de HQs com personagens fictícios, } \\
\text { foi construída uma história no gênero da literatura } \\
\text { fantástica, baseando-se na realidade de assistidos } \\
\text { (em tratamento ou já reabilitados). O propósito } \\
\text { da história foi o de fornecer compreensão sobre } \\
\text { características dos sintomas da doença (diagnóstico), } \\
\text { efeitos do tratamento e possibilidades de superação } \\
\text { (desmistificar o câncer como uma doença fatal). Os } \\
\text { alunos escreveram uma história e roteirizaram } 42 \\
\text { páginas para a construção da HQ. As primeiras doze } \\
\text { páginas estão disponíveis no ISSUU para a leitura } \\
\text { e avaliação do público, como forma de obter novos } \\
\text { direcionamentos sob a perspectiva da linguagem } \\
\text { gráfica. }{ }^{12}\end{array}$ \\
\hline
\end{tabular}

\begin{tabular}{|l|l|}
\hline PREMISSA & O aprendizado pode proporcionar a cura \\
\hline PROJETO & $\begin{array}{l}\text { Construção gráfica de livro de receitas para envolver } \\
\text { familiares e assistidos na feitura de refeições } \\
\text { saudáveis e apropriadas às dificuldades alimentares } \\
\text { provocadas pelo tratamento do câncer. }\end{array}$ \\
\hline OBJETIVO & $\begin{array}{l}\text { Produzir um livro de receitas saudáveis para crianças } \\
\text { e adolescentes. }\end{array}$ \\
\hline
\end{tabular}

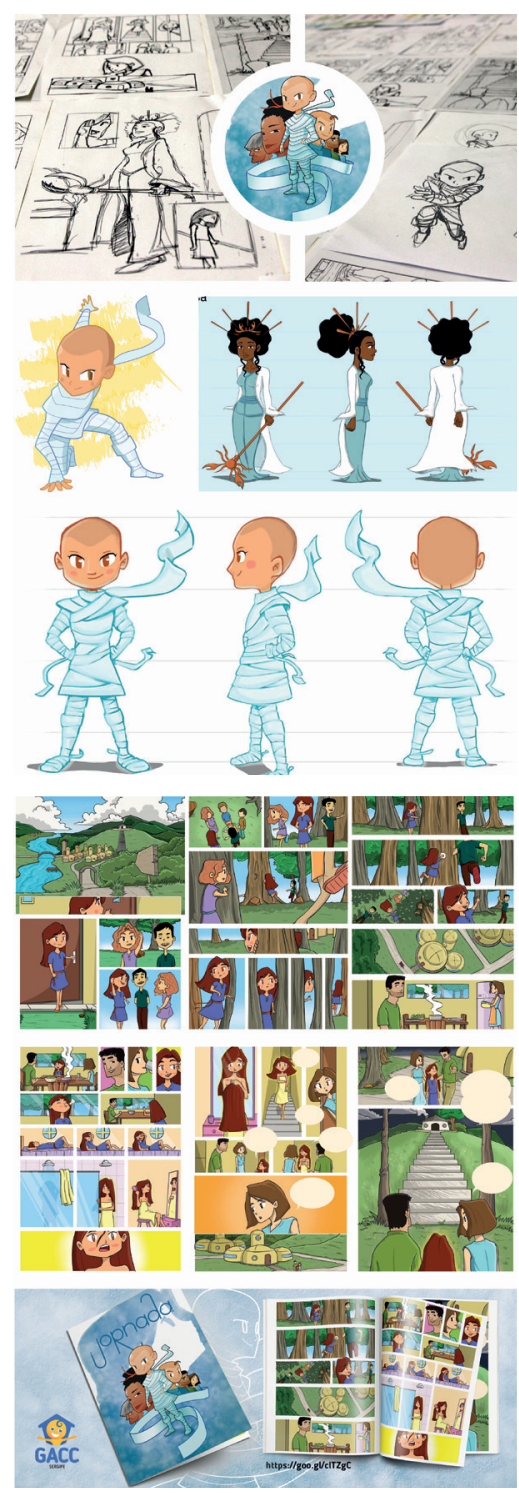

Painel panorâmico e páginas do projeto da HQ Jornada, resultado da premissa "O aprendizado pode proporcionar a cura". Fonte: Acervo do projeto.

\footnotetext{
${ }^{12}$ Disponivel em: <https://issuu.com/ germana_araujo/docs/jornada_gacc_ parte_i_a_descoberta_0>. Acesso em: 30 mar. 2017.
} 


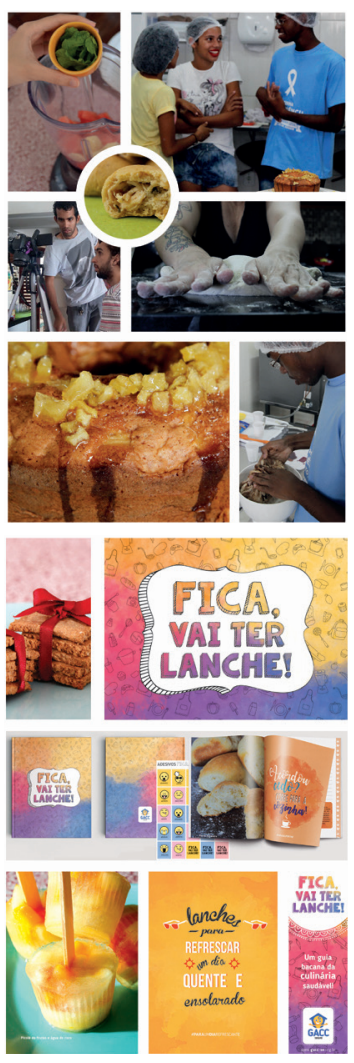

Painel panorâmico e páginas do projeto do livro de receitas Fica, vai ter lanche!, resultado da premissa "O aprendizado pode proporcionar a cura". Fonte: Acervo do projeto.

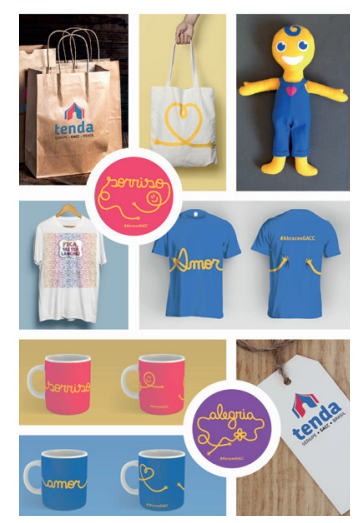

Painel panorâmico do projeto da grife Tenda, resultado da premissa "A sustentabilidade econômica pode garantir uma vida". Fonte: Acervo do projeto.

\begin{tabular}{|l|l|}
\hline \multirow{1}{*}{ PROPOSIÇão } & $\begin{array}{l}\text { Após verificar como o tratamento da criança } \\
\text { e do adolescente com câncer pode dificultar a } \\
\text { relação deles com os alimentos, foi proposta a } \\
\text { configuração de um livro com receitas saudáveis } \\
\text { para estimular novas práticas culinárias para } \\
\text { familiares e assistidos do GACC Sergipe. Todas as } \\
\text { receitas foram selecionadas com a orientação de } \\
\text { uma profissional da área de nutrição que trabalha } \\
\text { voluntariamente no GACC e testadas pelos alunos } \\
\text { com o auxílio de uma gastróloga. O livro Fica, vai } \\
\text { ter lanche! foi totalmente produzido pelos alunos, } \\
\text { e isso implica na produção de fotografias das } \\
\text { receitas, desenhos para indicar os processos de } \\
\text { feitura do alimento, projeto gráfico e diagramação. } \\
\text { Algumas das receitas foram para o canal Fica, vai } \\
\text { ter lanche! do YouTube como forma de ampliar o } \\
\text { estímulo ao envolvimento de adolescentes com a } \\
\text { prática da culinária saudável. }{ }^{13}\end{array}$ \\
\hline
\end{tabular}

\begin{tabular}{|l|l|}
\hline PREMISSA & A sustentabilidade econômica pode garantir uma vida \\
\hline PROJETO & Criação de uma linha de produtos da grife GACC. \\
\hline OBJETIVO & $\begin{array}{l}\text { Potencializar a sustentabilidade econômica da } \\
\text { instituição. }\end{array}$ \\
\hline PROPOSIÇÃo & $\begin{array}{l}\text { Segundo o resultado de diálogos com gestores da } \\
\text { instituição, a doação é uma atitude que em muitos } \\
\text { casos exige uma troca. Ou seja: pessoas fazem } \\
\text { a doação em espécie, mas cobram da instituição } \\
\text { um objeto em troca, um "brinde". Diante dessa } \\
\text { problemática, os alunos criaram uma marca comercial } \\
\text { para o GACC Sergipe, a grife Tenda, e desenvolveram o } \\
\text { projeto de alguns produtos para servirem de troca. }\end{array}$ \\
\hline
\end{tabular}




\begin{tabular}{|l|l|}
\hline REMISSA & Ser voluntário para ter ganhos mútuos \\
\hline PROJETO & Campanha em redes sociais \#abraceogacc. \\
\hline OBJETIVO & $\begin{array}{l}\text { Gerar o projeto da campanha \#abraceogacc, com } \\
\text { o propósito de estabelecer uma ligação íntima e } \\
\text { saudável entre as pessoas, prevendo a promoção } \\
\text { do engajamento da sociedade civil com as causas } \\
\text { do Gacc. }\end{array}$ \\
\hline PROPOSIÇÃo & $\begin{array}{l}\text { Tendo em vista o propósito de estimular a ação } \\
\text { voluntária para o Gacc Sergipe, buscou-se } \\
\text { compreender, com estudo bibliográfico e diálogo } \\
\text { com gestores dessa instituição, a importância de } \\
\text { uma campanha nas redes sociais e, posteriormente, } \\
\text { foram desenvolvidos temas de campanhas que } \\
\text { possivelmente pudessem gerar engajamento da } \\
\text { sociedade civil em ações voluntárias. } \\
\text { Junto com uma fotógrafa voluntária do Gacc Sergipe, } \\
\text { os alunos de design produziram as imagens das } \\
\text { crianças e adolescentes em tratamento do câncer } \\
\text { para desenvolver a campanha \#abraceogacc. } \\
\text { Buscou-se aproximação com as linguagens gráficas } \\
\text { de redes sociais para desenvolver a aparência dos } \\
\text { posts da campanha. }\end{array}$ \\
\hline
\end{tabular}

\begin{tabular}{|l|l|}
\hline PREMISSA & A autoestima floresce o amor \\
\hline PROJETO & $\begin{array}{l}\text { Oficina de produção fotográfica utilizando a técnica } \\
\text { pinhole. }\end{array}$ \\
\hline OBJETIVO & $\begin{array}{l}\text { Estimular a percepção da autoimagem com estima } \\
\text { positiva por adolescentes assistidos pelo GACC } \\
\text { Sergipe. }\end{array}$ \\
\hline
\end{tabular}

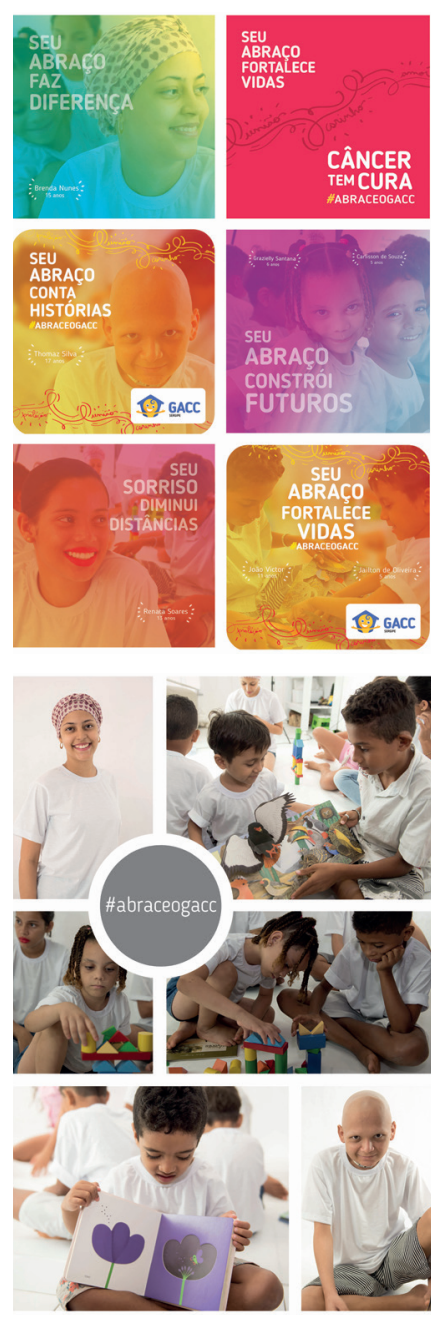

Painel panorâmico e peças gráficas da campanha \#abraceogacc, resultado da premissa "Ser voluntário para ter ganhos mútuos". Fonte: Acervo do projeto. 

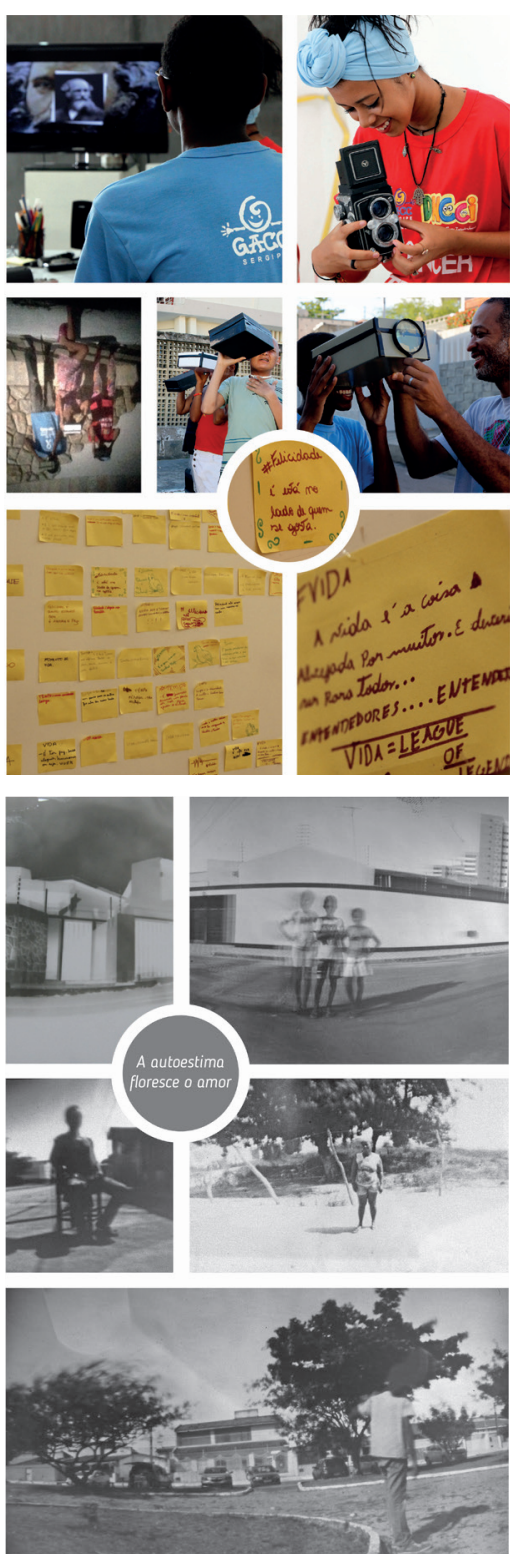

Painel panorâmico e produção

fotográfica da oficina de pinhole, resultado da premissa "A autoestima floresce o amor". Na foto, adolescentes assistidos pelo GACC Sergipe aprendem os princípios básicos da fotografia por intermédio da câmera escura construída com uma caixa de papelão.

Fonte: Acervo do projeto.

\begin{tabular}{|c|c|}
\hline PROPOSIÇÃO & $\begin{array}{l}\text { Tendo como foco a exploração dos princípios } \\
\text { básicos da fotografia por intermédio de processos } \\
\text { de aprendizagem colaborativa obtida pela técnica } \\
\text { pinhole, a oficina estimulou a produção da imagem a } \\
\text { partir de temas selecionados junto com os assistidos } \\
\text { que participavam da oficina: amor, felicidade e vida. } \\
\text { Junto com os alunos do curso de Design Gráfico da } \\
\text { UFS, adolescentes em tratamento confeccionaram as } \\
\text { câmeras com latas reutilizadas, fizeram a captura da } \\
\text { imagem (fotografia) e participaram do momento da } \\
\text { revelação dos negativos. Todo o processo proposto na } \\
\text { oficina foi de natureza colaborativa. } \\
\text { A técnica de pinhole foi escolhida para a produção } \\
\text { fotográfica desse projeto por causa dos seguintes } \\
\text { critérios: baixíssimo custo de produção da câmera - } \\
\text { propiciando que todo participante (adolescente) pudesse } \\
\text { construir e ter seu próprio equipamento fotográfico -; o } \\
\text { processo simples que proporciona a prática colaborativa, } \\
\text { no qual o adolescente participa de todas as etapas; o } \\
\text { exercício do ato reflexivo, proporcionado pelo tempo de } \\
\text { espera da captura da imagem - quebrando a ansiedade } \\
\text { constante causada por uma realidade cotidiana, na qual } \\
\text { quase tudo tem resposta imediata. } \\
\text { O propósito da produção fotográfica desse } \\
\text { projeto é ampliar a consciência perceptiva sobre a } \\
\text { autoimagem dos participantes e, a partir de então, } \\
\text { exercitar experiências artístico-culturais, reflexões } \\
\text { e críticas sobre o corpo no imaginário social, } \\
\text { ampliando possibilidades criativas e debates sobre } \\
\text { o autoconhecimento dos adolescentes envolvidos. } \\
\text { O debate sobre os temas que auxiliaram a produção } \\
\text { fotográfica dos adolescentes também foi uma } \\
\text { prática durante os encontros dos alunos de Design } \\
\text { com os assistidos. }\end{array}$ \\
\hline
\end{tabular}

Após o término dos projetos, compreendeu-se que projetar com base em diálogos efetuados em determinadas realidades também pode acarretar em situações obscuras. Interpretar a fala do outro não é uma tarefa 
simples e necessita, por parte do designer, de atenção, envolvimento pessoal e postura ética profissional. É preciso saber ouvir e ser sensivel à realidade do outro para saber devolver algo de interesse comum às partes envolvidas. Sem dúvida, o câncer é uma doença que se tornou frequente na sociedade e, possivelmente, alguns dos alunos de Design envolvidos no projeto tiveram proximidade com pessoas que sofreram com essa enfermidade. A convivência com a instituição e o diálogo com os assistidos fez com que os alunos de Design se colocassem no lugar no outro para preconceber ganhos com as proposições projetuais. Nesse sentido, releva-se o quão importante foi ter optado por uma metodologia de projeto que visasse o fortalecimento do aluno-designer enquanto produtor de conteúdos, e não somente como um aluno, atuando como um profissional, capaz de atender uma demanda já estabelecida por um possível cliente.
Painel panorâmico do projeto contendo imagens dos seis projetos desenvolvidos concomitantemente junto ao GACC Sergipe. Fonte: Acervo do projeto.
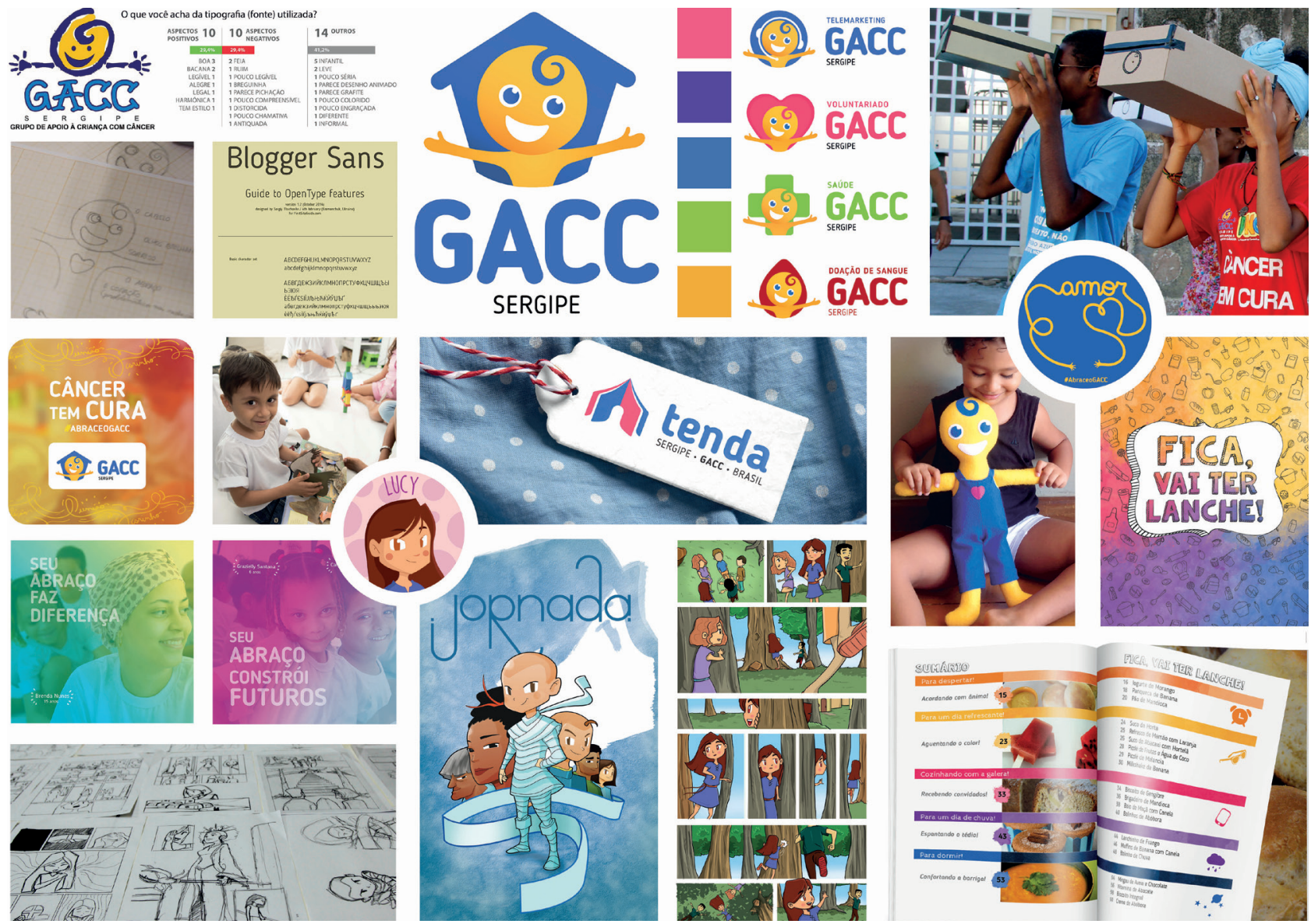


\section{CONCLUSÃO}

O resultado esperado de cada um desses seis projetos é mútuo entre o GACC e o discente da graduação do curso de Design da UFS.

A compreensão sobre a realidade dos assistidos do GACC, desconhecida pelos alunos até o momento em que se buscou o diálogo com a instituição, foi de fato impactante, interferindo de modo positivo e significativo tanto no engajamento desse aluno de Design com o desenvolvimento do projeto quanto nos resultados alcançados.

Revela-se o quão relevante é para um aluno de Design, um profissional em formação, a prática que une os saberes disciplinares aprendidos na academia à realidade sociocultural de determinados contextos, além da oportunidade de estar envolvido com projetos reais e não fictícios. Para o desenvolvimento de projetos reais, diferentemente dos exercícios acadêmicos de sala de aula, foi preciso lidar com questões éticas, como a aquisição de tipos ou o uso de tipografias de licença livre nos produtos e material de consumição, ou a produção de imagens próprias para não correr o risco de se ter que usar alguma imagem não autorizada disponível na internet. Premissas do Design Aplicadas ao GACC foi um projeto que inseriu o aluno de Design numa atividade criativa de perspectiva críticoreflexiva sobre a prática profissional.

Para a instituição/organização GACC Sergipe, esperou-se, por exemplo, que questões problemáticas da realidade cotidiana, como alimentação e superação dos assistidos e familiares, pudessem ser mais bem tratadas a partir das publicações (livro de receitas e HQ). Esperou-se, também, que a relação do GACC Sergipe com a sociedade civil pudesse crescer e, por intermédio do aumento da notoriedade da marca GACC gerenciada, pessoas manteriam ou iniciariam o engajamento com as causas da instituição (estímulo à ação voluntária).

Deve-se ter em vista que instituições como o GACC Sergipe são de suma importância para uma sociedade que apresenta séria precariedade no atendimento à saúde pública, e que somente a partir de sua assistência à população é possível realizar o diagnóstico e o tratamento de uma parcela significativa de crianças e adolescentes com câncer no estado de Sergipe. Diante dessa perspectiva trágica, dá-se relevo ao quão necessária é a 
realização de projetos de extensão que possam materializar a articulação do ensino e da pesquisa, de forma indissociável e viabilizadora de um novo futuro, visando à integração da UFS com a sociedade; nesse caso, do curso de Design com o GACC.

\section{REFERÊNCIAS}

ALBUQUERQUE JÚNIOR, Durval Muniz. Fragmentos do discurso cultural: por uma análise crítica do discurso sobre a cultura no Brasil. In: NAUSSBAUMER, Gisele Marchiori (Org.). Teoria e Políticas da Cultura: uma visão multidisciplinar. Coleção Cult. Salvador: EDUFBA, 2007, p. 13-23.

A feira dos mitos: a fabricação do folclore e da cultura popular (Nordeste 1920-1950) São Paulo: Intermeios, 2013.

BROWN, Tim. Design Thinking. uma metodologia poderosa para decretar o fim das velhas ideias. São Paulo: Elsevier, 2010.

CARDOSO, Rafael. Design para um mundo complexo. São Paulo: Cosac Naify, 2012.

Uma introdução à história do design. São Paulo: Blucher, 2008. Naify, 2005

O design brasileiro antes do design: aspectos da história gráfica. São Paulo: Cosac

MARGOLIN, V. O designer cidadão. Revista Design em Foco, Salvador, EDUNEB, v. III, n. 2, p. 145-150, jul./dez. 2006

MEGGS, Philip B.; PURVIS, Alston. História do Design Gráfico. Tradução: Cid Knipel. 4. ed. Rio de Janeiro: COSAC NAIFY, 2009

MIYASHIRO, Rafael Tadashi. Com design, além do design: os dois lados de um design gráfico com preocupações sociais. In: BRAGA, Marcos Cobra (Org.). O papel social do design gráfico: história, conceitos \& atuação. São Paulo: Senac, 2011, p. 65-85.

MORAES, Ana Maria; SANTA ROSA, José Guilherme. Design participativo, técnicas para inclusão de usuário no processo de ergonomia de interfaces. Rio de Janeiro: Rio Book's, 2012.

MUNARI, Bruno. Das coisas nascem coisas. Tradução: José Manuel de Vasconcelos. São Paulo: Martins Fontes, 1998.

NEVES, Flávia de Barros. Contestação gráfica: engajamento político-social por meio do design gráfico. In: BRAGA, Marcos Cobra (Org.). O papel social do design gráfico: história, conceitos \& atuação. São Paulo: Senac, 2011, p. 45-66.

PROEX. Disponivel em: <proex.ufs.br/pagina/27>. Acesso em: 19 out. 2016.

ROMERO, Mônica Pujol. Design: apontamentos para definir o campo. In: BELLUZO, Gisela; LEDESMA, Maria (Orgs.). Novas fronteiras do design gráfico. São Paulo: Estação das Letras e Cores, 2011.

RUBIM, A. A. C. A contemporaneidade como idade mídia. Interface_Comunicação, Saúde, Educação, v. 4, n. 7, p. 25-36, 2000. Disponivel em: <http://www.scielo.br/pdf/icse/v4n7/03. pdf>. Acesso em: 20 jan. 2016. 
